\title{
The effects of dry-rolled corn particle size on performance, carcass traits, and starch digestibility in feedlot finishing diets containing wet distiller's grains ${ }^{1,2}$
}

\author{
E. F. Schwandt, * J. J. Wagner, † T. E. Engle, † S. J. Bartle, \$. U. Thomson, \$ and C. D. Reinhardt*3 \\ *Department of Animal Sciences \& Industry and $†$ Department of Clinical Sciences, College of Veterinary Medicine, Kansas \\ State University, Manhattan 66506; and \$Department of Animal Sciences, Colorado State University, Fort Collins 80523
}

\begin{abstract}
Crossbred yearling steers $(n=360$; $395 \pm 33.1 \mathrm{~kg}$ initial BW) were used to evaluate the effects of dry-rolled corn (DRC) particle size in diets containing $20 \%$ wet distiller's grains plus solubles on feedlot performance, carcass characteristics, and starch digestibility. Steers were used in a randomized complete block design and allocated to 36 pens ( 9 pens/ treatment, with 10 animals/pen). Treatments were coarse DRC $(4,882 \mu \mathrm{m})$, medium DRC $(3,760 \mu \mathrm{m})$, fine DRC $(2,359 \mu \mathrm{m})$, and steam-flaked corn $(0.35 \mathrm{~kg} / \mathrm{L}$; SFC). Final BW and ADG were not affected by treatment $(P>0.05)$. Dry matter intake was greater and $\mathrm{G}: \mathrm{F}$ was lower $(P<0.05)$ for steers fed DRC vs. steers fed SFC. There was a linear decrease $(P<0.05)$ in DMI in
\end{abstract}

the final $5 \mathrm{wk}$ on feed with decreasing DRC particle size. Fecal starch decreased (linear, $P<0.01$ ) as DRC particle size decreased. In situ starch disappearance was lower for DRC vs. SFC $(P<0.05)$ and linearly increased $(P<0.05)$ with decreasing particle size at 8 and $24 \mathrm{~h}$. Reducing DRC particle size did not influence growth performance but increased starch digestion and influenced DMI of cattle on finishing diets. No differences $(P>0.10)$ were observed among treatments for any of the carcass traits measured. Results indicate improved ruminal starch digestibility, reduced fecal starch concentration, and reduced DMI with decreasing DRC particle size in feedlot diets containing 20\% wet distiller's grains on a DM basis.

Key words: dry rolled corn, fecal starch, feedlot, particle size

\section{INTRODUCTION}

Dry rolling corn is a common practice in feedlots located in the midwestern and northern Great Plains regions of the United States. Optimizing total tract starch utilization in diets containing dry-rolled corn (DRC) is essential for maximizing efficiency. However, recommendations often suggest that grain be coarsely cracked to refrain from producing an excessive amount of fine material that could potentially increase the rate of fermentation, reduce rumen $\mathrm{pH}$, and cause digestive disturbances (Owens et al., 1998).

\footnotetext{
${ }^{1}$ Contribution number 15-407-J from the Kansas Agriculture Experiment Station, Manhattan 66506.

${ }^{2}$ Pete Anderson and John Rakestraw of Midwest PMS, Loveland, $\mathrm{CO}$, and Erik Loe and Todd Milton.

${ }^{3}$ Corresponding author: cdr3@ksu.edu

Received June 10, 2015.

Accepted December 4, 2015.
}

Wet distiller's byproducts may be effectively used as a protein and energy source for feedlot finishing cattle (Larson et al., 1993; Ham et al., 1994; Watson et al., 2014) and can replace a portion of the DRC in the diet. Corrigan et al. (2009) reported that the inclusion of wet distiller's grains in finishing diets may influence the optimal grain processing method. Swanson et al. (2014) evaluated the effects of feeding coarse DRC $(2,680 \mu \mathrm{m})$ vs. fine DRC $(1,460 \mu \mathrm{m})$ in diets containing up to $40 \%$ dried distiller's grains with solubles (DDGS) and reported decreased DMI and increased G:F with increasing inclusion level of DDGS but that DRC particle size did not affect growth performance. In addition, carcass traits were not significantly influenced by DRC particle size or DDGS inclusion level.

In a survey conducted by Schwandt et al. (2015) evaluating DRC practices in feedlots located in the midwestern region of the United States $(n=31)$, the average geometric mean particle size $\left(\mathbf{d}_{\mathbf{g w}}\right)$ of DRC across all feed yards was $4,534 \pm 899^{\mu} \mu$ with a range of 2,167 to $6,823 \mu \mathrm{m}$. 
Table 1. Ingredient composition of study diets to evaluate dry-rolled corn particle size on feedlot performance in yearling steers fed a diet containing wet distiller's grain

\begin{tabular}{|c|c|c|c|c|c|}
\hline \multirow[b]{2}{*}{ Ingredient } & \multicolumn{5}{|c|}{ Diet $^{1}$} \\
\hline & Starter & Step-1 & Step-2 & Finish without ractopamine hydrochloride & Finish with ractopamine hydrochloride \\
\hline Wet distillers grains & 12.33 & 22.76 & 18.93 & 19.99 & 20.79 \\
\hline Corn $^{2}$ & 38.56 & 39.04 & 57.44 & 64.90 & 63.10 \\
\hline Corn silage & 17.25 & 26.71 & 13.61 & 8.75 & 7.18 \\
\hline Alfalfa hay & 28.58 & 8.79 & 5.30 & - & - \\
\hline Liquid supplement ${ }^{3}$ & 3.27 & 2.68 & 4.71 & 6.36 & 6.47 \\
\hline Medicated pellet ${ }^{4}$ & - & - & - & - & 2.46 \\
\hline
\end{tabular}

\footnotetext{
${ }^{1}$ Starter period (d 1-7 after arrival), Step-1 (fed d 8-14 after arrival), Step-2 (fed d 15-23 after arrival), finish without ractopamine hydrochloride (d 24-113 after arrival), and finish with ractopamine hydrochloride (d 114-142 after arrival).

${ }^{2}$ Steam-flaked corn was included in the starter and step-up diets for all treatments.

${ }^{3}$ Contained $40 \% \mathrm{CP}, 33.71 \% \mathrm{CP}$ from NPN, $0.6 \%$ fat, $6.1 \%$ calcium, $0.15 \%$ phosphorus, $3 \%$ salt, $2 \%$ potassium, $28,650 \mathrm{IU} / \mathrm{kg}$ vitamin A, $551 \mathrm{mg} / \mathrm{kg}$ monensin, and $115.7 \mathrm{mg} / \mathrm{kg}$ tylosin (Midwest PMS, Firestone, CO).

${ }^{4}$ Scott Pro Optaflexx pellet, $882 \mathrm{mg} / \mathrm{kg}$, added to the batch at $0.34 \mathrm{~kg}$ per animal daily (Elanco Animal Health, Greenfield, IN).
}

The objective of this study was to evaluate the effects of DRC particle size on animal performance, carcass traits, and starch digestibility in feedlot finishing diets containing $20 \%$ wet distiller's grains on a DM basis.

\section{MATERIALS AND METHODS}

The study was conducted in accordance with a protocol approved by Colorado State University Institutional Animal Care and Use Committee (14-5091A).

\section{Animals}

Crossbred yearling steers $(n=360$; initial $\mathrm{BW}=$ $395 \pm 33.1 \mathrm{~kg}$ ) were used in a randomized complete block design to evaluate the effects of DRC particle size in diets containing $20 \%$ wet distiller's grains on feedlot performance, carcass characteristics, and starch digestibility. Steers originated from northcentral Oklahoma and were shipped approximately $1,100 \mathrm{~km}$ to the Agriculture Research, Development \& Education Center (ARDEC; Fort Collins, CO). Cattle received long-stemmed hay and water on arrival at the facility for the first $24 \mathrm{~h}$. Starter diet and ground grass hay were fed until processing on $\mathrm{d} 7$ and 8 after arrival.

Steers were individually weighed on 2 consecutive days ( 7 and 8 after arrival) to determine an initial BW and were divided into 9 weight block replicates, each consisting of 40 steers, and randomly allocated to 1 of 4 treatments. Steers were vaccinated against infectious bovine rhinotracheitis virus, type I and type II bovine virus diarrhea, parainfluenza-3, and bovine respiratory syncytial virus (Bovi-Shield Gold; Zoetis, Kalamazoo, MI) and clostridial bacterin-toxoid (Ultra Choice 7; Zoetis) and treated for parasites (Noromectin [injectable ivermectin; Norbrook Laboratories Limited, Norbrook, Lenexa, KS] and Safe-Guard [fenbendazole; Merck Animal Health, Summit, NJ]). Steers were implanted with Revalor-
XS (40 mg estradiol and $200 \mathrm{mg}$ of trenbolone acetate; Merck Animal Health) administered in the right ear and were not reimplanted before slaughter. Steers were housed in 10 animals per pen where they received their dietary treatment throughout the duration of the study. Each pen measured 6.1 by $40 \mathrm{~m}$ and contained a 22.3$\mathrm{m}^{2}$ concrete feeding apron and $6.1 \mathrm{~m}$ of bunk space, and each 2 adjacent pens shared a common continual flow water fountain. Pen was used as the experimental unit.

Dietary treatments were coarse DRC $(4,882 \mu \mathrm{m}$; COARSE), medium DRC $(3,760 \mu \mathrm{m}$; MEDIUM), fine DRC $(2,359 \mu \mathrm{m}$; FINE), and steam-flaked corn $(0.35 \mathrm{~kg} / \mathrm{L}$; SFC). All diets contained $20 \%$ wet distiller's grains (DM basis) and were formulated to meet or exceed NRC (2000) requirements for growing-finishing beef cattle. Wet distiller's grains inclusion level was based on the data from a survey by Vasconcelos and Galyean (2007) that reported an average inclusion level of grain coproducts (DM basis) in finishing diets of $16.5 \%$, with the majority of producers feeding $20 \%$.

Steers were transitioned to the finishing diet over a 23-d period following arrival using a series of 4 diets (Table 1) including starter (d 1-7), Step-1 (fed d 8-14), Step-2 (fed d 15-23), finisher without ractopamine hydrochloride (d 24-113), and finisher with ractopamine hydrochloride (d 114-142). Steam-flaked corn was used in the starter and step-up diets and all diet changes during the step-up program were simultaneous for all pens and all treatments. Steers were allocated to treatment pens (study d 1) on d 8 after arrival and received the finishing diet containing the appropriate corn treatment for the first time on $\mathrm{d} 24$ after arrival (study d 17). Bunk reading was conducted daily at $0700 \mathrm{~h}$, and steers were fed 1 time daily using a Mohrlang 452c feed truck (MMI International, Brush, CO) equipped with scales accurate to the nearest $4.54 \mathrm{~kg}$. Complete mixed diet and feed ingredient samples were collected weekly for DM and nutrient content determination (Table 2). Target 
Table 2. Analyzed nutrient composition of diets used to evaluate the effects of dry-rolled corn particle size on feedlot yearling steers

\begin{tabular}{|c|c|c|c|c|c|c|c|}
\hline \multirow[b]{2}{*}{ Item } & \multicolumn{7}{|c|}{$\operatorname{Diet}^{1}$} \\
\hline & Starter & Step-12 & Step-2 $2^{2}$ & COARSE & MEDIUM & FINE & SFC \\
\hline$\overline{\mathrm{DM}}$ & 65.0 & 55.8 & 59.3 & 62.6 & 61.1 & 61.4 & 60.4 \\
\hline $\mathrm{CP}$ & 14.1 & 15.2 & 15.0 & 15.7 & 15.9 & 16.3 & 16.2 \\
\hline $\mathrm{NPN}^{3}$ & 1.8 & 1.5 & 2.8 & 3.2 & 3.2 & 3.3 & 2.9 \\
\hline NDF & 29.1 & 22.1 & 17.8 & 14.2 & 14.5 & 13.9 & 14.6 \\
\hline Fat & 2.97 & 4.89 & 4.16 & 5.2 & 5.2 & 5.2 & 5.1 \\
\hline $\mathrm{Ca}$ & 0.94 & 0.46 & 0.65 & 0.83 & 0.71 & 0.88 & 0.80 \\
\hline $\mathrm{P}$ & 0.29 & 0.36 & 0.35 & 0.37 & 0.37 & 0.37 & 0.40 \\
\hline K & 1.46 & 1.10 & 0.94 & 0.83 & 0.84 & 0.84 & 0.88 \\
\hline $\mathrm{Mg}$ & 0.27 & 0.22 & 0.18 & 0.19 & 0.19 & 0.19 & 0.20 \\
\hline S & 0.20 & 0.23 & 0.19 & 0.24 & 0.20 & 0.20 & 0.20 \\
\hline Starch & 34.5 & 42.0 & 50.7 & 53.2 & 54.0 & 54.3 & 52.0 \\
\hline
\end{tabular}

${ }^{1}$ COARSE $=$ coarse dry-rolled corn $(4,882 \mu \mathrm{m}) ;$ MEDIUM $=$ medium dry-rolled corn $(3,760 \mu \mathrm{m})$; FINE $=$ fine dry-rolled corn $(2,359 \mu \mathrm{m})$; $\mathrm{SFC}=$ steam-flaked corn $(0.35 \mathrm{~kg} / \mathrm{L})$

${ }^{2}$ Step-1 (fed d 8-14) and step-2 (fed d15-23)

${ }^{3}$ Crude protein equivalent.

nutrient concentrations for the finishing diet were $16 \%$ $\mathrm{CP} ; 3 \% \mathrm{CP}$ from NPN; $4.5 \% \mathrm{NDF}$ from diet corn silage; $0.72 \% \mathrm{Ca}$; and $90 \mathrm{mg}$ supplemental $\mathrm{Zn}, 20 \mathrm{mg}$ supplemental $\mathrm{Cu}$, and $75 \mathrm{mg}$ supplemental $\mathrm{Mn}$ per kilogram DM. Rumensin (Elanco Animal Health, Indianapolis, IN) and Tylan (Elanco Animal Health) were included in all diets. Target Rumensin dosage was 24.5, 24.5, 36.7, and $48.9 \mathrm{mg} / \mathrm{kg}$ in the starter, Step-1, Step-2, and finisher diets, respectively. Optaflexx (Elanco Animal Health, Greenfield, IN) was fed to all treatments the final 29 d in the feedlot at $30.1 \mathrm{mg} / \mathrm{kg}$ dry matter basis, providing approximately $300 \mathrm{mg}$ per animal ${ }^{-1} \cdot \mathrm{d}^{-1}$.

Steers were pen weighed on study d 17 (d 24 after arrival) before the initial feeding of the finishing diets. Final individual BW was obtained before feeding on study d 132 and steers remained on their respective dietary treatments until slaughter on d 136 of the study. A $4 \%$ shrink was applied to all BW data before statistical analysis. On the day of slaughter, steers were shipped approximately $49 \mathrm{~km}$ to a commercial abattoir in Greeley, $\mathrm{CO}$, and randomly presented for slaughter using standard USDA Food Safety and Inspection Service inspection criteria. Carcass data including HCW, 12th rib fat depth, rib eye area, USDA yield grade, marbling score, and USDA quality grade were collected by trained Colorado State University meats specialists.

\section{Corn Processing}

A common corn supply was used for all DRC treatments. Dry-rolled corn was processed once weekly at the ARDEC using an electric-powered single-stage roller mill (R \& R Machine Works, Dalhart, TX) with two
Table 3. Nutrient analysis ${ }^{1}$ for corn used to evaluate the effects of dry-rolled corn particle size on feedlot finishing diets containing $20 \%$ wet distiller's grains

\begin{tabular}{lccc}
\hline \hline Item $^{2}$ & DM & Total starch & Available starch \\
\hline FINE & $86.9(0.26)$ & $73.5(1.03)$ & $19.8(0.66)$ \\
MEDIUM & $86.7(0.42)$ & $74.0(0.76)$ & $20.0(0.32)$ \\
COARSE & $86.9(0.63)$ & $74.2(0.72)$ & $20.0(0.32)$ \\
SFC & $83.5(0.51)$ & $76.7(0.92)$ & $43.0(2.98)$ \\
\hline
\end{tabular}

${ }^{1}$ SDK Laboratories, Hutchinson, KS.

${ }^{2} \mathrm{FINE}=$ fine dry-rolled corn $(2,359 \mu \mathrm{m})$; MEDIUM = medium dryrolled corn $(3,760 \mu \mathrm{m})$; COARSE = coarse dry-rolled corn $(4,882 \mu \mathrm{m})$; $\mathrm{SFC}=$ steam-flaked corn $(0.35 \mathrm{~kg} / \mathrm{L} ; \mathrm{SE}$ of the mean $)$.

${ }^{3}$ Available starch. Percentage of as-fed, (SE) of the mean, total starch evaluated by enzymatic hydrolysis.

25.4 by $50.8 \mathrm{~cm}$ rolls with 3.2 corrugations per centimeter. Corn processed for the COARSE and MEDIUM treatments were passed through dial settings 8 and 9.5, respectively. Corn processed for the FINE treatment was initially processed using the MEDIUM setting and then and returned through the roller mill at dial setting 17 to achieve the FINE particle size. Steam-flaked corn was manufactured weekly at Ault Feedmill, LLC (Ault, $\mathrm{CO}$ ) and transported approximately $32 \mathrm{~km}$ to the feedlot facility. Target density for the SFC was $0.35 \mathrm{~kg} / \mathrm{L}$, starch availability averaged $43.0 \%$, and the total starch content of the corn averaged $76.7 \%$ (Table 3 ).

Particle size analysis was conducted weekly on DRC samples. The average particle size within each sample is described as the $\mathrm{d}_{\mathrm{gw}}$, and log normal SD (Sgw) represents the range of particle size within each sample. The dgw and Sgw were calculated using equations presented in the standard method for measure fineness of feed materials (ANSI/ASAE S319.2 FEB03; ASAE, 1993) at the Kansas State University Feed Technology Innovation Center (Manhattan, KS). Each DRC sample was initially divided using a riffle divider, and a 100-g subsample was sieved through a set of 13 circular sieves (model RX-29; W.S. Tyler Ro-Tap, Mentor, OH) for 15 min. Each shaken sieve was individually weighed (Table 4). Analysis was completed in duplicate and an average of the duplicates was reported. If there was not a $97 \%$ or greater recovery of the initial weight from the shaken samples, the sample was reanalyzed.

\section{Fecal Starch}

Fecal starch was evaluated on d 79, 114, and 132 of the study, which correspond to 63,91 , and $119 \mathrm{~d}$ on the finishing diets, respectively. Approximately $300 \mathrm{~g}$ of freshly voided feces were collected from ground piles of the first 6 individual steers to defecate per pen for all pens in the study for each collection period. Samples were composited by pen within each sampling date and 
Table 4. Dry-rolled corn particle sizes used to evaluate the effects of dry-rolled corn particle size on feedlot finishing diets containing $20 \%$ wet distiller's grains

\begin{tabular}{|c|c|c|c|c|c|}
\hline \multirow[b]{2}{*}{ Item $^{1}$} & \multicolumn{3}{|c|}{ Treatment $^{2}$} & \multirow[b]{2}{*}{ SEM $^{3}$} & \multirow{2}{*}{$\begin{array}{l}\text { Probability } \\
\quad>F\end{array}$} \\
\hline & COARSE & MEDIUM & FINE & & \\
\hline$\overline{d_{g w}}$ & 4,882 & 3,760 & 2,359 & 127.6 & $<0.01$ \\
\hline$\underline{\mathrm{S}_{\mathrm{gw}}}$ & 1,539 & 1,711 & 2,001 & 55.3 & $<0.01$ \\
\hline \multicolumn{6}{|c|}{$\begin{array}{l}{ }^{1} d_{\mathrm{gw}}=\text { geometric mean particle size }(\mu \mathrm{m}) ; \mathrm{Sgw}=\log \text { normal } \mathrm{SD} \text { of the } \\
\text { geometric mean diameter. }\end{array}$} \\
\hline \multicolumn{6}{|c|}{$\begin{array}{l}{ }^{2} \text { COARSE }=\text { coarse dry-rolled corn }(4,882 \mu \mathrm{m}) ; \text { MEDIUM }=\text { medium } \\
\text { drv-rolled corn }(3,760 \mu \mathrm{m}) \cdot \text { FINE }=\text { fine dry-rolled corn }(2.359 u \mathrm{um})\end{array}$} \\
\hline
\end{tabular}

frozen. Fecal samples were analyzed for moisture, DM, and total starch content at the Kansas State University Ruminant Nutrition Laboratory (Manhattan], KS) using enzymatic hydrolysis (Technicon Industrial method number SE3-0036FJ4). Samples were analyzed in duplicate, and those samples that differed in total starch content between duplicates by $5 \%$ or greater were reanalyzed. Duplicates were averaged (Table 5).

\section{In Situ DM Disappearance and Starch Digestibility}

Two mature crossbred steers (BW $\geq 725 \mathrm{~kg}$ ) fitted with rumen cannula were fed gradually decreasing amounts of low-quality mixed grass hay and increasing amounts of the SFC-based finishing diet (Table 1) over a 14-d adaptation period followed by ad libitum amounts of the SFC-based finishing diet for an additional $7 \mathrm{~d}$ before the start of the in situ study. One gram of unmasticated SFC, COARSE, MEDIUM, and FINE samples were placed into separate Dacron bags $(10$ by $20 \mathrm{~cm}$; Ankom Inc., Fairport, NY) with an average pore size of $50 \mu \mathrm{m}$, and the bags were sealed. Four bags per time period $(0,2,4,8,12$, and $24 \mathrm{~h})$ per steer $(n=2)$ were used. All samples were suspended in the rumen at times appropriate for the desired incubation time interval and removed simultaneously. Upon removal, all samples were individually hand washed for approximately 20 s per bag under a continuous stream of lukewarm tap water. Samples that were not incubated were washed using the same procedure and were used to determine the amount of sample that was washed out.

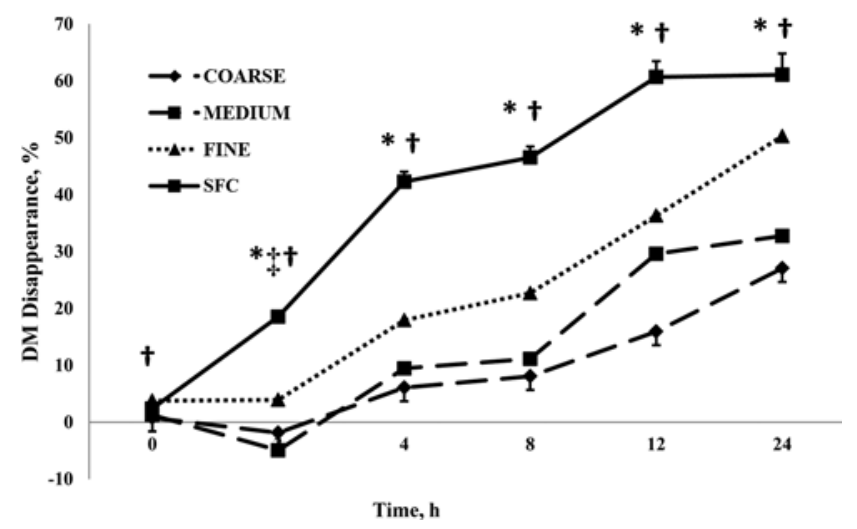

Figure 1. The effects of corn processing treatment on ruminal DM disappearance from corn samples placed in Dacron bags and suspended in the rumen for $0,2,4,8,12$, and $24 \mathrm{~h}$. Treatments were coarse dryrolled corn $(4,882 \mu \mathrm{m}$; COARSE), medium dry-rolled corn $(3,760 \mu \mathrm{m}$; MEDIUM), fine dry-rolled corn $(2,359 \mu \mathrm{m}$; FINE), and steam-flaked corn $(0.35 \mathrm{~kg} / \mathrm{L} ; \mathrm{SFC})$. *SFC vs. dry-rolled corn (DRC), $P<0.05$; †DRC quadratic, $P<0.05$; †DRC linear, $P<0.05$ (SEM 5.30).

Washed in situ bags were dried for $48 \mathrm{~h}$ at $60^{\circ} \mathrm{C}$ in a forced-air oven to determine in situ DM disappearance (Fig. 1). Residual corn samples were removed from the bags, composited by time period, ground with a mortar and pestle, and frozen. A 50-mg subsample was weighed and analyzed for starch disappearance at the Kansas State University Ruminant Nutrition Laboratory using enzymatic hydrolysis. Samples were analyzed in duplicate and if samples differed in total starch between duplicates by $5 \%$ or greater, they were reanalyzed. Duplicates were averaged (Fig. 2).

\section{Statistical Analysis}

Fecal starch, feedlot performance, and continuous carcass data were analyzed on a pen mean basis, and DRC particle size data were analyzed on a collection mean basis as a randomized complete block design using PROC MIXED of SAS (SAS Inst. Inc., Cary, NC). Treatment (TRT) was included in the model as a fixed class variable and weight block pen replicate was included in the model as a random effect. Average daily DMI for each week was evaluated using MIXED model procedures with TRT, week, and TRT $\times$ week included in the model as fixed effects.

Table 5. Least squares means illustrating the effect of dry-rolled corn particle size on fecal starch content in yearling steers fed diets containing $20 \%$ wet distiller's grains

\begin{tabular}{|c|c|c|c|c|c|c|c|c|c|}
\hline \multirow[b]{2}{*}{ Item } & \multicolumn{4}{|c|}{ Treatment $^{1}$} & \multirow[b]{2}{*}{ SEM $^{2}$} & \multicolumn{4}{|c|}{ Probability $>F^{3}$} \\
\hline & COARSE & MEDIUM & FINE & SFC & & TRT & SFC vs. DRC & DRC linear & DRC quadratic \\
\hline Fecal starch, $\%$ of DM & 13.92 & 10.41 & 7.64 & 2.12 & 0.594 & $<0.01$ & $<0.01$ & $<0.01$ & 0.66 \\
\hline
\end{tabular}




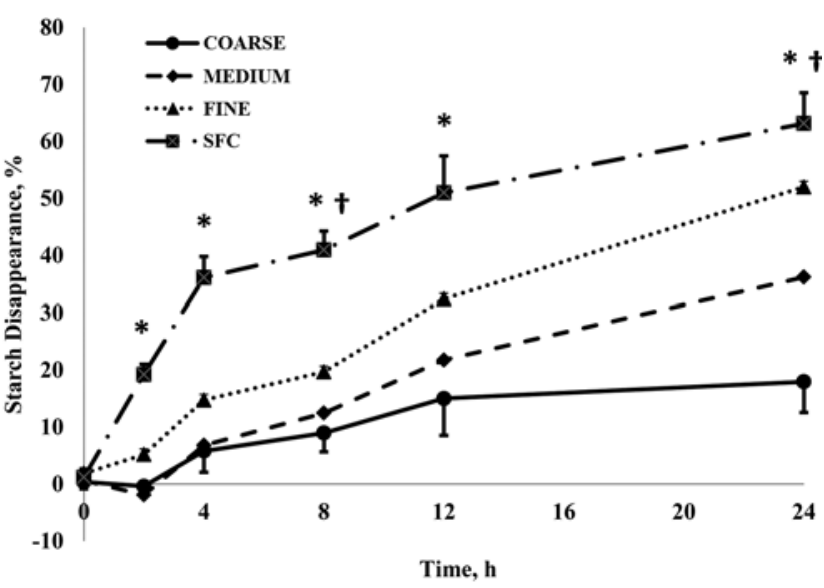

Figure 2. The disappearance of starch from Dacron bags suspended in the rumen for $0,2,4,8,12$, or $24 \mathrm{~h}$. Treatments were coarse dry-rolled corn (4,882 $\mu \mathrm{m}$; COARSE), medium dry-rolled corn ( $3,760 \mu \mathrm{m}$; MEDIUM), fine dry-rolled corn $(2,359 \mu \mathrm{m} ; \mathrm{FINE})$, and steam-flaked corn $(0.35 \mathrm{~kg} / \mathrm{L} ; \mathrm{SFC})$. Treatment $(P<0.01)$, time $(P<0.01)$, and the treatment $\times$ time interaction $(P<0.01)$ effects for in situ starch disappearance were significant. After a 24-h incubation, in situ starch disappearance was approximately $18.0,36.2,52.0$, and $63.1 \%$ (SEM 5.44) for the COARSE, MEDIUM, FINE, and SFC treatments, respectively ( ${ }^{*} \mathrm{SFC}$ vs. dry-rolled corn [DRC], $P<0.05$; †DRC linear, $P<0.05$ ).

Quality grade (Low Choice and greater vs. Select and lower) and yield grade (yield grades 1,2 , or $3 \mathrm{vs}$. yield grades 4 and 5) data were evaluated as categorical responses using PROC GLIMMIX of SAS and assuming a binomial distribution. The Link $=$ Logit option of the model statement and the ILINK option of the LSMEANS statement were used to calculate the likelihood \pm SEM that an individual within each pen qualified for a specific category. Significance was determined at $P \leq 0.05$. Pen initial BW was used as a covariate in the analysis of feedlot performance during the diet step-up period (d 1-16) or overall cumulative feedlot performance (d 1-132) and d 17 pen BW was used as a covariate in the analysis of feedlot performance during the finishing period (d 17-132) when the covariate effect was significant $(P \leq 0.10)$. Treatment means were separated using orthogonal contrasts if the effect for TRT approached significance $(P \leq 0.05)$. Contrasts of interest were SFC vs. DRC and the linear and quadratic effects of decreasing particle size among the DRC treatments.

\section{RESULTS AND DISCUSSION}

\section{Cattle Health}

Very few respiratory issues were encountered during the study. A total of 7 steers either died or were removed from the study: 3 from the SFC treatment, 2 from the FINE treatment, 1 from the MEDIUM treatment, and 1 from the COARSE treatment. All statistical analysis excluded animals that died before study termination.

\section{Feed Ingredient and Diet Nutrient Analysis}

The SFC used for the study had slightly lower $(P \leq$ 0.05) DM than the DRC. Corn used for the DRC treatments was from a common source, and therefore, nutrient profiles are similar among the DRC treatments. Corn used for the SFC treatment was from a different source and may have contained slightly lower NDF and slightly greater starch compared with the DRC. Available starch was measured using enzymatic hydrolysis (SDK Laboratories, Hutchinson, KS) and as a percentage of total starch was over 2-fold greater for the SFC vs. DRC. This large increase in available starch for SFC compared with DRC likely has a much larger effect on potential performance differences compared with relatively minor differences in total starch concentration. Total starch concentrations as well as the concentrations for other analyzed nutrients were similar among all treatments.

The COARSE, MEDIUM, and FINE $\mathrm{d}_{\mathrm{gw}}$ were $4,882 \pm 93.9,3,760 \pm 166.0$, and 2,359 $\pm 112.3 \mu \mathrm{m}$, respectively $(P<0.01$; Table 2$)$. The DRC Sgw averaged $1,539,1,711$, and $2,001 \mu \mathrm{m}$ for the COARSE, MEDIUM, and FINE, respectively $(P<0.01)$. Achieving consistency within the grain processing procedures for each DRC treatment was critical to maintain an acceptable distribution between treatments throughout the duration of the study. Dry-rolled corn dgw and Sgw were different $(P<$ $0.01)$ between treatments. Differences in Sgw distribution might have influenced total tract starch digestion. As particle size decreases, Sgw increases, indicating a wider particle size range, which might have influenced rumen function and digestibility different between DRC treatments. The larger the Sgw, the wider the distribution of particle size (Stark and Chewning, 2012). This may be a contributing factor to the rate and site of starch digestion and should be evaluated when determining improved total tract starch digestion with decreasing particle size of DRC. Additionally, to achieve FINE particle size, the corn had to be processed twice, which likely is unrealistic in most operations. Two- or 3-stage roller mills would be more equipped to achieve a finer, more consistent particle size.

Corn in situ DM disappearance was 18.5, 31.4, 58.7, and $70.2 \%$, for the COARSE, MEDIUM, FINE, and SFC treatments, respectively (Fig. 2). These results are in agreement with Galyean et al. (1981), who reported increased in situ DM and starch disappearance for 12- and 24-h incubation periods with smaller DRC particle sized; however, consideration of percentage of fines $(<750 \mu \mathrm{m})$ may be important in determining the extent of ruminal digestion. Although differences in DM disappearance for larger particle sizes $(6,000$ and $3,000 \mu \mathrm{m})$ were not different, DM disappearance values were nearly double as particle size decreased from 3,000 to $750 \mu \mathrm{m}$ (Galyean et al., 1981). In the present 
Table 6. Least squares means illustrating the effect of dry-rolled corn particle size on feedlot performance in yearling steers fed diets containing $20 \%$ wet distiller's grains

\begin{tabular}{|c|c|c|c|c|c|c|c|c|c|}
\hline \multirow[b]{2}{*}{ Item $^{1}$} & \multicolumn{4}{|c|}{ Treatment $^{2}$} & \multirow[b]{2}{*}{$\mathrm{SEM}^{3}$} & \multicolumn{4}{|c|}{ Probability $>F^{4}$} \\
\hline & COARSE & MEDIUM & FINE & SFC & & TRT & SFC vs. DRC & DRC linear & $\overline{\text { DRC quadratic }}$ \\
\hline Initial weight, kg & 381 & 381 & 381 & 381 & 9.4 & 0.76 & 0.58 & 0.50 & 0.49 \\
\hline Day 17 weight, $\mathrm{kg}^{5}$ & 412 & 420 & 418 & 416 & 2.0 & 0.06 & 0.99 & 0.08 & 0.07 \\
\hline Final weight, $\mathrm{kg}^{6}$ & 637 & 640 & 636 & 641 & 4.5 & 0.81 & 0.60 & 0.87 & 0.42 \\
\hline \multicolumn{10}{|l|}{ Step-up period } \\
\hline $\mathrm{ADG}, \mathrm{kg}$ & 1.83 & 2.31 & 2.16 & 2.11 & 0.122 & 0.06 & 0.99 & 0.10 & 0.07 \\
\hline DMI, $\mathrm{kg}^{5}$ & 8.23 & 8.38 & 8.51 & 8.43 & 0.120 & 0.39 & & & \\
\hline $\mathrm{G}: \mathrm{F}$ & 0.223 & 0.277 & 0.254 & 0.250 & 0.0138 & 0.07 & 0.96 & 0.16 & 0.05 \\
\hline Calc. NEm ${ }^{7}$ & 99.4 & 113.5 & 107.2 & 106.0 & 3.69 & 0.08 & 0.86 & 0.18 & 0.05 \\
\hline Calc. $\mathrm{NEg}^{7}$ & 68.6 & 81.0 & 75.4 & 74.3 & 3.24 & 0.08 & 0.86 & 0.18 & 0.05 \\
\hline \multicolumn{10}{|l|}{ Finish period } \\
\hline $\mathrm{ADG}, \mathrm{kg}$ & 1.98 & 1.93 & 1.91 & 1.96 & 0.040 & 0.61 & & & \\
\hline DMI, $\mathrm{kg}^{6}$ & 12.31 & 12.15 & 12.17 & 11.50 & 0.256 & 0.11 & 0.02 & 0.68 & 0.77 \\
\hline $\mathrm{G}: \mathrm{F}^{6}$ & 0.162 & 0.159 & 0.158 & 0.171 & 0.0035 & 0.05 & $<0.01$ & 0.43 & 0.84 \\
\hline Calc. NEm ${ }^{7}$ & 88.9 & 88.5 & 88.0 & 93.5 & 1.35 & 0.03 & $<0.01$ & 0.69 & 0.97 \\
\hline Calc. $\mathrm{NEg}^{7}$ & 59.3 & 59.0 & 58.6 & 63.4 & 1.19 & 0.03 & $<0.01$ & 0.69 & 0.97 \\
\hline DMI last 5 wk, kg & 13.05 & 12.50 & 12.22 & 11.27 & 0.216 & $<0.01$ & $<0.01$ & $<0.01$ & 0.15 \\
\hline \multicolumn{10}{|l|}{ Overall } \\
\hline $\mathrm{ADG}, \mathrm{kg}^{5}$ & 1.97 & 2.00 & 1.96 & 2.00 & 0.034 & 0.80 & 0.58 & 0.50 & 0.49 \\
\hline DMI, $\mathrm{kg}^{5}$ & 11.82 & 11.70 & 11.73 & 11.14 & 0.233 & 0.14 & 0.02 & 0.77 & 0.78 \\
\hline caFinal BW, $\mathrm{kg}^{8}$ & 635 & 642 & 637 & 639 & 4.6 & 0.74 & 0.088 & 0.076 & 0.26 \\
\hline $\mathrm{caADG}, \mathrm{kg}^{8}$ & 1.96 & 2.00 & 1.97 & 1.99 & 0.035 & 0.79 & 0.83 & 0.82 & 0.29 \\
\hline $\mathrm{G}: \mathrm{F}^{5}$ & 0.168 & 0.171 & 0.168 & 0.180 & 0.0030 & 0.03 & $<0.01$ & 0.87 & 0.47 \\
\hline Calc. NEm ${ }^{7}$ & 90.0 & 91.0 & 90.0 & 94.9 & 1.23 & 0.02 & $<0.01$ & 0.99 & 0.55 \\
\hline Calc. $\mathrm{NEg}^{7}$ & 60.4 & 61.2 & 60.3 & 64.7 & 1.08 & 0.02 & $<0.01$ & 0.99 & 0.55 \\
\hline \multicolumn{10}{|c|}{${ }^{1}$ Least squares treatment mean. } \\
\hline \multicolumn{10}{|c|}{$\begin{array}{l}{ }^{2} \text { COARSE }=\text { coarse dry-rolled corn }(4,882 \mu \mathrm{m}) ; \text { MEDIUM }=\text { medium dry-rolled corn }(3,760 \mu \mathrm{m}) ; \text { FINE }=\text { fine dry-rolled corn }(2,359 \mu \mathrm{m}) ; \mathrm{SFC}= \\
\text { steam-flaked corn }(0.35 \mathrm{~kg} / \mathrm{L}) .\end{array}$} \\
\hline \multicolumn{10}{|c|}{${ }^{3}$ Standard error of the least squares mean. } \\
\hline \multicolumn{10}{|c|}{${ }^{4} \mathrm{TRT}=$ treatment $($ as a fixed model effect); DRC $=$ dry-rolled corn. } \\
\hline \multicolumn{10}{|c|}{${ }^{5}$ Initial BW used as a covariate $(P<0.10)$} \\
\hline \multicolumn{10}{|c|}{${ }^{6}$ Day $17 \mathrm{BW}$ used as a covariate $(P<0.10)$} \\
\hline${ }^{7}$ Calc. $=$ calculated & alculated fro & performanc & Ical/45.4 & iet DM). & & & & & \\
\hline
\end{tabular}

study, comparing the MEDIUM to FINE treatments, decreasing the particle size by $1,400 \mu \mathrm{m}$ increased DM disappearance by $27.3 \%$. These results suggest improved DM disappearance with decreasing particle size of DRC and over a 2-fold difference when decreasing particle size from MEDIUM to FINE particle size.

After a 24-h incubation, in situ starch disappearance was approximately 18.0, 36.2, 52.0, and $63.1 \pm 5.44 \%$ for the COARSE, MEDIUM, FINE, and SFC treatments, respectively (SFC vs. DRC, $P<0.05$; DRC linear, $P<$ $0.05)$. Treatment $(P<0.01)$, time $(P<0.01)$, and the treatment $\times$ time interaction $(P<0.01)$ effects for in situ starch disappearance were significant (Fig. 2). These results indicate increased ruminal starch disappearance with decreased DRC particle size and agree with Galyean et al. (1981), who demonstrated increased in situ starch digestion as DRC particle size was reduced. An interaction between particle size and time is most likely due to greater starch availability in SFC compared with DRC and could contribute to increased starch disappearance (Galyean et al., 1981). Additionally, differences in SFC starch disappearance are consistent with previous research evaluating rumen digestibility of SFC compared with ground or cracked corn (Ørskov et al., 1969; Galyean et al., 1976). Total tract starch digestibility is affected by grain processing, which greatly affects the rate and extent of digestion of starch in the rumen (Theurer, 1986). Although treatment differences for starch disappearance were not as large as those differences seen for DM disappearance, there was a linear effect of particle size on starch disappearance at 8 and $24 \mathrm{~h}(P<0.05)$, indicating that decreasing DRC particle size increases starch digestibility in the rumen, thus likely contributing to improved total tract starch digestion.

Fecal starch concentrations can be used as an indicator of assessing total tract starch digestion with a high 
Table 7. Least squares means illustrating the effect of dry-rolled corn particle size on carcass merit in yearling steers fed diets containing $20 \%$ wet distiller's grains

\begin{tabular}{|c|c|c|c|c|c|c|}
\hline \multirow[b]{2}{*}{ Item $^{1}$} & \multicolumn{4}{|c|}{ Treatment $^{2}$} & \multirow[b]{2}{*}{ SEM $^{3}$} & \multirow[b]{2}{*}{ Probability $>F$} \\
\hline & COARSE & MEDIUM & FINE & SFC & & \\
\hline$\overline{\mathrm{HCW}},{ }^{4} \mathrm{~kg}$ & 419 & 423 & 420 & 422 & 3.2 & 0.79 \\
\hline Dressing percentage & 65.8 & 66.2 & 66.1 & 65.8 & 0.25 & 0.49 \\
\hline Marbling score, units ${ }^{5}$ & 409 & 420 & 413 & 408 & 8.0 & 0.67 \\
\hline USDA quality grade ${ }^{6}$ & 10.5 & 10.6 & 10.5 & 10.5 & 0.11 & 0.81 \\
\hline \multicolumn{7}{|c|}{ USDA quality grade distribution ${ }^{7}$} \\
\hline$\geq$ Low Choice & 52.3 & 53.4 & 56.3 & 52.4 & 5.45 & 0.94 \\
\hline$\leq$ Select & 47.7 & 46.6 & 43.7 & 47.6 & & \\
\hline 12th rib fat depth, $\mathrm{cm}$ & 1.30 & 1.32 & 1.30 & 1.37 & 0.051 & 0.70 \\
\hline Rib eye area, $\mathrm{cm}^{2}$ & 91.6 & 91.0 & 91.0 & 91.6 & 1.16 & 0.81 \\
\hline USDA yield grade ${ }^{8}$ & 3.14 & 3.25 & 3.20 & 3.26 & 0.088 & 0.71 \\
\hline \multicolumn{7}{|c|}{ USDA yield grade distribution ${ }^{7}$} \\
\hline Yield grades 1, 2, and 3 & 87.5 & 86.2 & 86.0 & 86.9 & & \\
\hline Yield grades 4 and 5 & 12.5 & 13.8 & 14.0 & 13.1 & 3.99 & 0.99 \\
\hline
\end{tabular}

${ }^{1}$ Least squares treatment means unless specified otherwise.

${ }^{2}$ COARSE $=$ coarse dry-rolled corn $(4,882 \mu \mathrm{m}) ;$ MEDIUM $=$ medium dry-rolled corn $(3,760 \mu \mathrm{m}) ;$ FINE $=$ fine dry-rolled corn $(2,359 \mu \mathrm{m}) ; \mathrm{SFC}=$ steam-flaked corn $(0.35 \mathrm{~kg} / \mathrm{L})$.

${ }^{3}$ Standard error of the least squares mean.

${ }^{4}$ Initial weight was used a covariant in the analysis $(P<0.10)$

${ }^{5}$ Marbling score units: $400=$ Small00, $500=$ Modest 00.

${ }^{6}$ Quality grade numeric scale: $10=$ Select; $11=$ Low Choice; $12=$ Average Choice.

${ }^{7}$ Percentage of individual carcasses within a treatment qualifying for each category.

${ }^{8}$ USDA yield grade calculated from carcass measurements.

correlation of $R^{2}=0.91$ and $R^{2}=0.97$ (Zinn et al., 2002; Corona et al., 2005), respectively. Zinn et al. (1995) evaluated the influence of intake on total tract starch digestibility and determined that corn processing is the primary factor affecting site and extent of starch digestion. Huntington et al. (2006) reported that the main limit to improved cattle performance from the dietary use of starch is the amount that is digested and absorbed from the small intestine. As grain is more extensively processed, the amount of starch reaching the small intestine is reduced (steam flaking, high moisture, and fine grinding; Theurer, 1986). Fecal starch was lower $(P<$ 0.01; Table 6) for the SFC vs. the COARSE, MEDIUM, and FINE treatments. Reduced fecal starch indicates greater starch digestion for SFC compared with DRC. Fecal starch concentration linearly decreased $(P<0.01)$ with decreasing DRC particle size, indicating improved total tract starch digestion as DRC particle size is reduced. These results are in agreement with Galyean et al. (1979), who reported improved total tract starch digestion with decreasing particle size; however, Turgeon et al. (1983) determined that starch postruminally digested was not influenced by corn particle size, suggesting that improved total tract starch digestion was due to extent of ruminal digestion. Owens and Soderlund (2006) reported that postruminal particle size reduction is minimal, indicating improved starch digestion would be attributed to more extensively processed grain or increased surface area for improved microbial and enzymatic digestion. Furthermore, particle size contributes to the efficiency of total tract starch digestion by the amount of endosperm cells exposed to microbial and enzymatic digestion (McAllister et al., 2006). Decreased fecal starch concentrations with decreasing DRC particle size could be attributed to improvements in both ruminal and postruminal starch digestion.

\section{Feedlot Performance}

Following the step-up period, study d 1 to 16 , average pen BW tended $(P=0.06)$ to be influenced by treatment (Table 6) and averaged 412, 420, and $418 \mathrm{~kg}$ for the COARSE, MEDIUM, and FINE treatments, respectively (linear, $P=0.08$; quadratic, $P=0.07$ ). Day 17 BW was therefore used as a covariate to evaluate feedlot performance during the finishing period (d 17-132). During the finishing period, ADG was not different $(P$ $>0.10)$ among treatments. Dry matter intake for SFC compared with DRC was different $(P=0.02)$ during the finishing period. Additionally, on closer evaluation, DMI was reduced $(P<0.01)$ for the SFC vs. the DRC treatments and the DRC (linear, $P<0.01$ ) treatments during the final $5 \mathrm{wk}$ of the finishing period. This reduction in DMI resulted in improved feed efficiency $(P<$ 
0.01 ) and NE recovery (approximately $7.5 \%$ for NEg) for the SFC vs. the DRC treatments. Performance measures among the DRC treatments were not different $(P>$ 0.10 ), which agrees with previous research (Swanson et al., 2014). Reduced DMI and improved G:F (6.9\%) for the SFC vs. the DRC treatments suggests that investments in steam flaking equipment remain a viable option for all but the very smallest capacity cattle feeders. Additionally, because there was a linear effect of decreasing DMI with reduced particle size of DRC and no differences in animal performance or carcass traits for DRC treatments, this suggests that a potential subacute acidotic event could have occurred. Owens et al. (1998) reported that feed intake and growth performance can be compromised when subacute acidosis occurs.

The treatment $\times$ week interaction was significant $(P$ $<0.05$; Fig. 3), indicating the effect of treatment on DMI depended on which weeks of the study were considered. In addition, over the final $5 \mathrm{wk}$ of the study, linear $(P<$ $0.01)$ effects of DRC particle size on DMI were observed (13.05, 12.50, and $12.22 \mathrm{~kg} /$ animal for the COARSE, MEDIUM, and FINE treatments, respectively).

\section{Carcass Merit}

No differences $(P>0.10)$ among treatments were observed for any of the carcass traits measured, suggesting that corn processing did not impact carcass merit in yearling steers fed diets containing $20 \%$ wet distiller's grain (Table 7). These results are similar to results reported by Swanson et al. (2014) in that decreasing DRC particle size with the inclusion of 20 and $40 \%$ DDGS had no effect on HCW, 12th rib fat thickness, rib eye area, and marbling score.

Our results indicate improved ruminal starch digestibility, reduced fecal starch concentration, and reduced DMI with decreasing DRC particle size in feedlot diets containing 20\% wet distiller's grains on a DM basis. A better understanding of DRC particle size on the influence of feedlot performance with the addition of various levels of wet distiller's grains is needed. Based on these data, feeding finely processed corn in diets containing 20\% wet distiller's grains appears to be acceptable in binding fines and improving homogeneity of diet; however, the reason for reduced DMI with decreasing DRC particle size toward the end of the finishing period is not clear and potentially could have been associated with a subacute acidotic event. Reducing DRC particle size in diets containing wet distiller's grains plus solubles may improve starch digestion, but additional processing increases the cost of production and may not be offset by improved cattle performance. Furthermore, given that DRC particle size had a linear effect on fecal starch concentrations

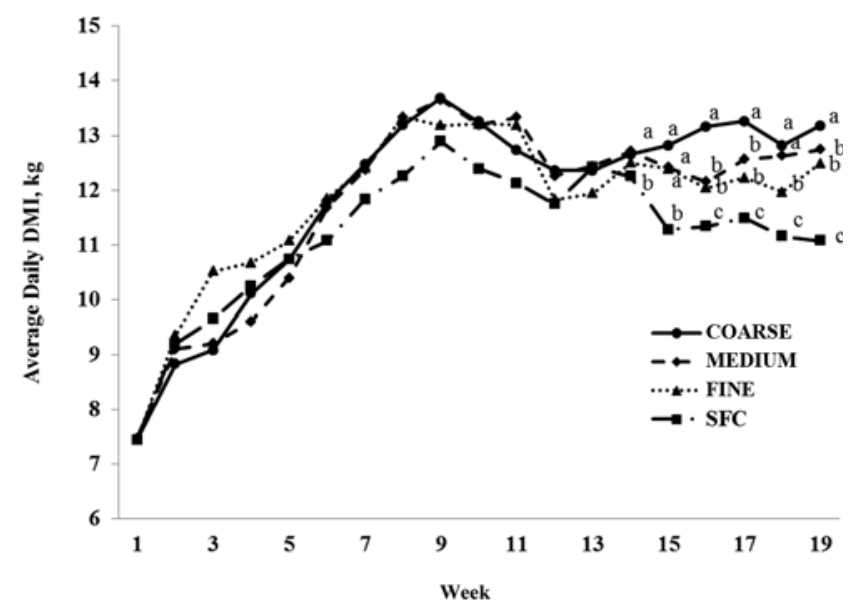

Figure 3. Weekly average daily DMI by treatment for cattle fed coarse dry-rolled corn $(4,882 \mu \mathrm{m}$; COARSE), medium dry-rolled corn (3,760 $\mu \mathrm{m}$; MEDIUM), fine dry-rolled corn ( $2,359 \mu \mathrm{m}$; FINE), and steamflaked corn $(0.35 \mathrm{~kg} / \mathrm{L} ; \mathrm{SFC})$. Treatment $\times$ week interaction was significant $(P<0.05) .{ }^{\mathrm{a}-\mathrm{c}}$ For any given week, means without a common superscript are different $(P<0.05$ [SEM 0.501]).

in this study, reducing the particle size from current manufacturing practices of the industry average would improve total tract starch utilization and potentially reduce DMI in diets containing 20\% wet distiller's grains.

\section{LITERATURE CITED}

American Society of Agricultural Engineers (ASAE). 1993. Method of determining and expressing fineness of feed by sieving. ASAE standard ASAE S319.2. ASAE, St. Joseph, MO.

Corona, L., S. Rodriguez, R. A. Ware, and R. A. Zinn. 2005. Comparative effects of whole, ground, dry-rolled, and steam flaked corn on digestion and growth performance in feedlot cattle. Prof. Anim. Sci. 21:200-206.

Corrigan, M. E., G. E. Erickson, T. J. Klopfenstein, M. K. Luebbe, K. J. Vander Pol, N. F. Meyer, C. D. Buckner, S. J. Vanness, and K. J. Hanford. 2009. Effect of corn processing method and corn wet distillers grains plus solubles inclusion level in finishing steers. J. Anim. Sci. 87(10):3351-3362. doi:10.2527/jas.2009-1836.

Galyean, M. L., D. G. Wagner, and R. R. Johnson. 1976. Site and extent of starch digestion in steers fed processed corn rations. J. Anim. Sci. 43:1088-1094.

Galyean, M. L., D. G. Wagner, and F. N. Owens. 1979. Corn particle size and site and extent of digestion by steers. J. Anim. Sci. 49:204-210.

Galyean, M. L., D. G. Wagner, and F. N. Owens. 1981. Dry matter and starch disappearance of corn and sorghum as influenced by particle size and processing. J. Dairy Sci. 64(9):18041812. doi:10.3168/jds.S0022-0302(81)82769-5.

Ham, G. A., R. A. Stock, T. J. Klopfenstein, E. M. Larson, D. H. Shain, and R. P. Huffman. 1994. Wet corn distillers byproducts compared with dried corn distillers grains with solubles as a source of protein and energy for ruminants. J. Anim. Sci. 72:3246-3257.

Huntington, G. B., D. L. Harmon, and C. J. Richards. 2006. Sites, rates, and limits of starch digestion and glucose metabolism in growing cattle. J. Anim. Sci. 84(E. Suppl.):E14-E24. 
Larson, E. M., R. A. Stock, T. J. Klopfenstein, M. H. Sindt, and R. P. Huffman. 1993. Feeding value of wet distillers byproducts for finishing ruminants. J. Anim. Sci. 71:2228-2236.

McAllister, T. A., D. J. Gibb, K. A. Beauchemin, and Y. Wang. 2006. Starch type, structure and ruminal digestion. In: Ok. State Univ. Cattle Grain Proc. Symp. MP-177, Oklahoma City, OK. p. 30-41.

NRC. 2000. Nutrient requirements of beef cattle. 7th rev. ed. Update 2000. Natl. Acad. Press, Washington, DC.

Ørskov, E. R., C. Fraser, and R. N. B. Kay. 1969. Dietary factors influencing the digestion of starch in the rumen and small and large intestine of early weaned lambs. Br. J. Nutr. 23(02):217-226. doi:10.1079/BJN19690029.

Owens, F. N., D. S. Secrist, W. J. Hill, and D. R. Gill. 1998. Acidosis in cattle: A review. J. Anim. Sci. 76:275-286.

Owens, F. N., and S. Soderlund. 2006. Ruminal and postruminal starch digestion by cattle. In: Ok. State Univ. Cattle Grain Proc. Symp. MP-177, Oklahoma City, OK. p. 116-128.

Schwandt, E. F., D. U. Thomson, S. J. Bartle, and C. D. Reinhardt. 2015. A survey of dry-processed-corn particle size and fecal starch in midwestern United States feedlots. Prof. Anim. Sci. 31(5):467-472. doi:10.15232/pas.2015-01392.

Stark, C. R., and C. G. Chewning. 2012. The effect of sieve agitators and dispersing agent on the method of determining and expressing fineness of feed materials by sieving. Anim. Prod. Sci. 52(1):69-72. doi:10.1071/AN11124.
Swanson, K. C., A. Islas, Z. E. Carlson, R. S. Goulart, T. C. Gilbery, and M. L. Bauer. 2014. Influence of dry-rolled corn processing and increasing dried corn distillers grain plus solubles inclusion for finishing cattle on growth performance and feeding behavior. J. Anim. Sci. 92(6):2531-2537. doi:10.2527/jas.2013-7547.

Theurer, B. C. 1986. Grain processing effects on starch utilization by ruminants. J. Anim. Sci. 63:1649-1662.

Turgeon, O. A., Jr., D. R. Brink, and R. A. Britton. 1983. Corn particle size mixtures, roughage level, and starch utilization in finishing steer diets. J. Anim. Sci. 57:739-749.

Vasconcelos, J. T., and M. L. Galyean. 2007. Nutritional recommendations of feedlot consulting nutritionists: The 2007 Texas Tech University survey. J. Anim. Sci. 85:2772-2781. doi: $10.2527 /$ jas.2007-0261.

Watson, A. K., K. J. Vander Pol, T. J. Huls, M. K. Lubbe, G. E. Erickson, T. J. Klopfenstein, and M. A. Greenquist. 2014. Effect of dietary inclusion of wet or modified distillers grains plus solubles on performance of finishing cattle. Prof. Anim. Sci. 30:585-596. doi:10.15232/pas.2013-01302.

Zinn, R. A., C. F. Adam, and M. S. Tamayo. 1995. Interaction of feed intake level on comparative ruminal and total tract digestion of dry-rolled and steam-flaked corn. J. Anim. Sci. 73:1239-1245.

Zinn, R. A., F. N. Owens, and R. A. Ware. 2002. Flaking corn: Processing mechanics, quality standards, and impacts on energy availability and performance of feedlot cattle. J. Anim. Sci. 80:1145-1156. 